\title{
TÉCNICA PARA O POSICIONAMENTO CONFIÁVEL DE PONTOS DE LEVANTAMENTO DE CAMPO, NAS IMAGENS DE SATÉLITE COM USO DE GPS NAVEGADOR DE BAIXO CUSTO
}

\author{
Francisco Darío Maldonado ${ }^{12}$; Enzo D’Arco ${ }^{2}$ \\ ${ }^{1}$ Centro de Fotogrametría, Cartografía y Catastro. Universidad Nacional de \\ San Juan-UNSJ, Argentina. < francis@dsr.inpe.br > \\ ${ }^{2}$ Doutorando em Sensoriamento Remoto. Instituto Nacional de Pesquisas \\ Espaciais-MCT/INPE-Brasil. < enzo@dsr.inpe.br >
}

\section{Resumo}

Neste trabalho foi definida uma metodologia ao alcance de profissionais não especializados em sistema GPS (Sistema Global de Posicionamento) para obter, de forma confiável, a posição de um ponto amostral no levantamento de campo sobre uma imagem de resolução média como LandsattTM. Utilizando GPS navegador de baixo custo na modalidade automática de coleta de pontos (tracking), sobre dois pontos da Rede Fundamental do IBGE, o qual possui uma precisão milimétrica, coletou-se 100 pontos com intervalos de 1 minuto entre cada medição. Repetiu-se a coleta nos dois pontos em dois dias diferentes, onde sobre os dados obtidos foram realizados os testes estatísticos de normalidade, de média. Uma precisão adequada em relação ao tamanho dos pixels das imagens de satélite, foi obtida após 20 minutos de amostragem com o GPS, com erro médio de 5 metros. Outra vantagem foi eliminar a possibilidade de marcar o ponto durante uma deriva exageradamente fora da leitura do GPS, aumentando a confiabilidade das posições das amostras obtidas no levantamento de campo.

Palavras-chave: GPS, levantamento de campo, imagens de satélite. 


\section{Abstract}

In this paper a methodology reaching professionals not specialized in GPS (Global Positioning System) was defined in order to trustworthily obtain the sample point position of field data on an average resolution image such as Landsat / TM. Using a low cost GPS navigator with millimetric precision in the automatic mode for point collecting (tracking), over two points of IBGE Fundamental Network, 100 points with 1 minute interval between each measurement were collected. This process was repeated over the two points in two different days. Using the obtained data, the statistic tests of normality and mean were performed. After 20 minutes of GPS sampling with an error average of 5 meters, an adequate precision in relation to the size of the satellite image pixels was obtained. Another advantage was to eliminate the possibility of establishing the point during a drifting which is extremely out of PGS reading, increasing the confidence of the sample positions obtained in the field work.

\section{Introdução}

Uma campanha de campo para o levantamento da vegetação geralmente não utiliza para posicionar os pontos um receptor GPS (Sistema de Posicionamento Global) de precisão, em razão do alto custo e dos riscos de danos no equipamento. Assim, usando GPS navegador de baixo custo se torna um dado importante o conhecimento da precisão da posição alcançada. Por outro lado, em levantamentos de campo, nos quais são coletados dados ambientais, o tempo de permanência no sitio amostral é normalmente considerável. Este tempo de amostragem pode ser aproveitado para aumentar a precisão do posicionamento das amostras, mediante procedimentos estatísticos.

O sistema GPS funciona com o mesmo princípio da rádio navegação, em sua estrutura final o sistema conta com uma constelação de 24 satélites distribuídos em 6 órbitas distintas. Com esta configuração em qualquer ponto sobre a superfície da Terra ou próximo a ela há um mínimo de quatro satélites acima do horizonte 24 horas por dia. Os satélites ficam a uma altura de $20.200 \mathrm{~km}$, têm um período (duração de uma volta ao redor da Terra) de 12 horas e uma inclinação da órbita em relação ao plano do equador de $55^{\circ}$ e permitem o posicionamento em três dimensões, latitude, longitude e altitude (Airleve, 2003). 


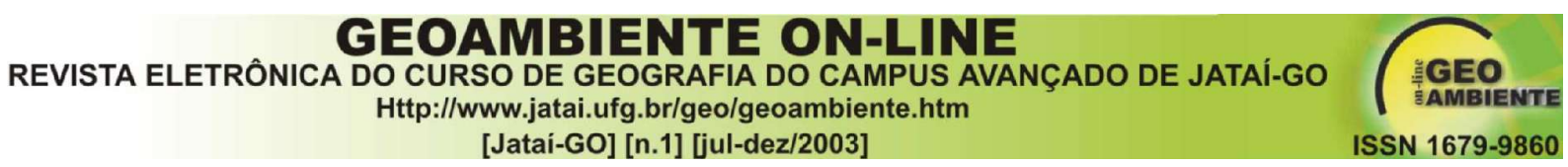

A precisão de um GPS navegador, era inicialmente da ordem dos 100, a partir de 1 de Maio de 2000 o governo norte-americano, proprietário do sistema, deixou de introduzir um erro no sistema, erro propositadamente introduzido no serviço público para segurança do estado norte-americano, e que tornou este sistema mais preciso. Este erro foi definitivamente abolido, porém na prática o sistema possui variações intrínsecas expressiveis (Mehaffrey e Yaezel, 2003; Wilson, 2003).

Neste documento são chamados de "deriva" o desvio que um instrumento sofre com o tempo, a partir do ponto de repouso, quando a variável medida e as condições ambientes permanecem constantes. Chama-se de "precisão" a exatidão dos cálculos da posição do ponto. Na Figura 1, mostra-se uma situação típica onde o transecto de $50 \mathrm{~m}$ de longitude usado para amostragem da vegetação do semi-árido e posicionado com o GPS no ponto médio, e deve ser associado confiávelmente a um pixel da imagem TM. O transecto é um método de análise botânico de uma certa área, o qual consiste em delimitar uma faixa desta, devidamente medida, e contar as plantas incluídas, a fim de obter uma caracterização da vegetação.

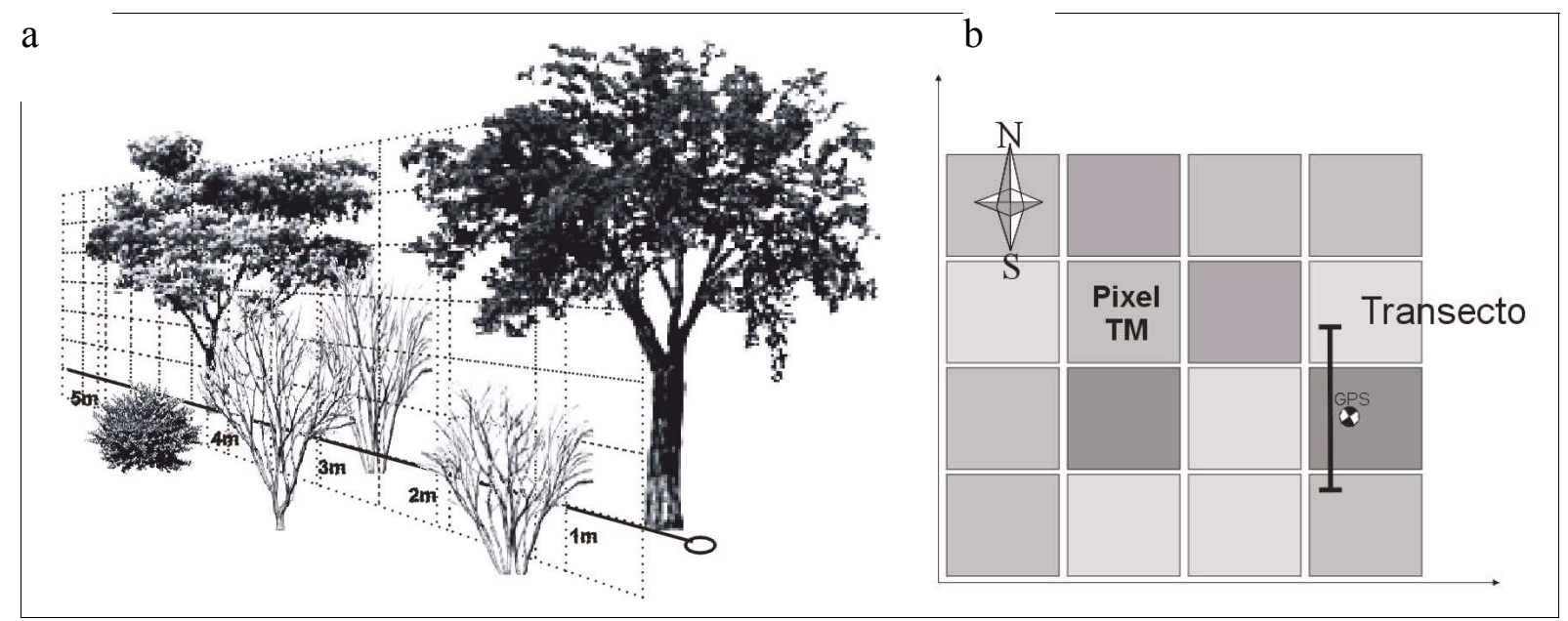

Fig. 1- a) Esquema do Transecto; b) Esquema do levantamento sobre uma imagem, nota-se o tamanho do transecto relativo ao pixel TM, e o ponto da leitura do GPS, para seu posicionamento. 


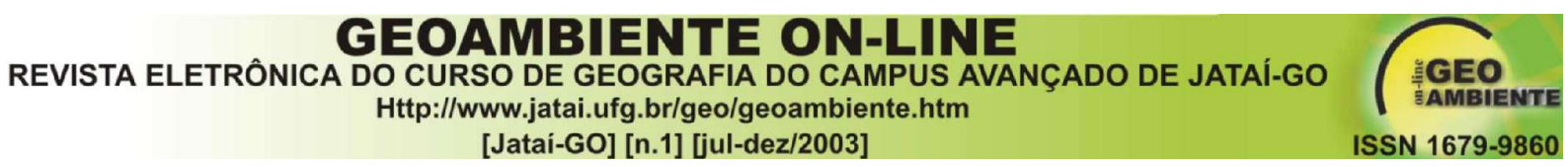

A atual necessidade de posicionamento confiável dos transectos nas imagens está motivada pelo uso de técnicas supervisionadas de classificação e de detecção de mudanças nas imagens digitais; estas exigem certeza na identificação do pixel amostrado a campo. Assim, com a utilização do GPS, a confiabilidade da posição pode ser melhorada de alguma forma. Neste trabalho é proposto um caminho para a melhora da confiabilidade do posicionamento mantendo aceitáveis os custos da pesquisa. O objetivo é lograr uma técnica para obter de forma confiável a posição do ponto amostrado nas imagens orbitais com uso de receptor GPS de baixo custo.

\section{Materiais}

Foram utilizados dois pontos da Rede Fundamental do IBGE localizados na sede do Instituto Nacional de Pesquisas Espaciais (INPE), São José dos Campos - SP, posicionados com uma precisão da ordem de $1 \mathrm{~mm}$, no sistema UTM WGS84. Os pontos se encontram em situação de entorno aberto, sem prédios nem árvores de grande porte nas proximidades, como pode ser visto na Figura $2 b$.

a
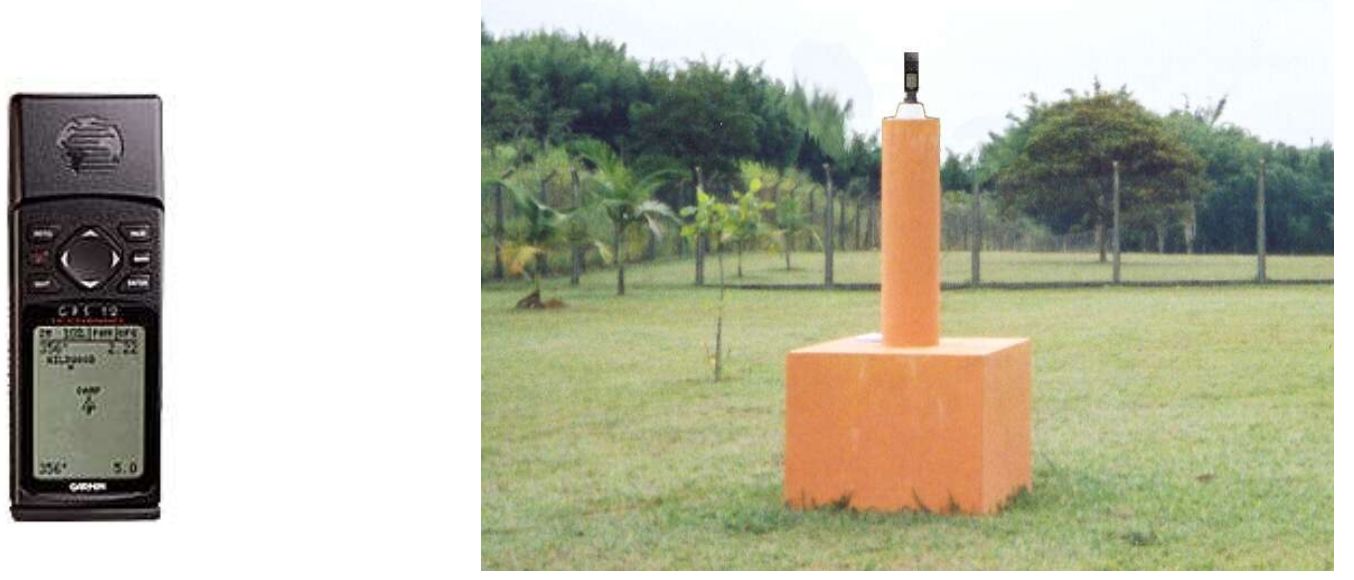

Fig. 2 - a) Receptor GPS navegador e b) Ponto da Rede Fundamental do IBGE com o receptor em posição de toma de dados no topo do monumento. 
Foram realizadas duas leituras no ponto IBGE SAT 91536 e duas no ponto IBGE SAT 91537, para verificar a acurácea do aparelho em relação ao dado de referência.

O receptor de GPS utilizado foi o Garmin 12, sem antena externa, adquirido em 1998 e ainda não foi atualizado o software como é recomendado por Garmin (Garmin, 2003). Desta forma, o aparelho encontra-se nas condições de uso normais de um usuário sem os conhecimentos sobre a manutenção do receptor.

Os softwares utilizados para os processamentos dos dados do GPS foram:

- GPS TrackMaker 11.8, para comunicação entre o receptor/computador e também, para a geração do arquivo ASCII de coordenadas geográficas. Este software é de dominio publico e pode ser obtido pela internet no seguinte endereço: $<$ http://www.gpstm.com/>.

- MATLAB 6.0 Release 12, para analise espacial e estatística dos dados com o modulo Statistic Toolbox.

\section{Método}

Foram realizadas coletas automáticas de pontos (Trackpoints) de minuto em minuto durante aproximadamente 1 hora e 30 minutos em cada ponto amostral em dois dias diferentes, para a obtenção de uma quantidade razoável de pontos que permitissem a análise estatística posterior das leituras. Esta possibilidade existe nos receptores GPS navegadores e esta opção é usada para traçar um percurso de forma automática. Pode-se aproveitar esta caracteristica do navegador para gravar vários pontos com fins de obter um valor médio após a exportação dos dados para o computador . Esta opção esta disponível como mostra a Figura 3. Na Figura 3a mostra o erro estimado de posição de cada leitura e na Figura $3 b$ é mostrada a opção da seleção automática de minuto em minuto. 
a

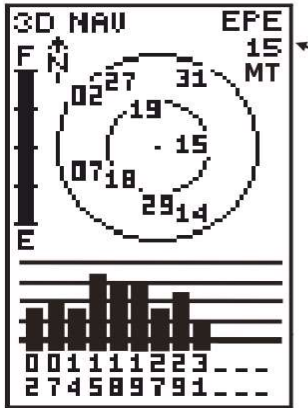

b

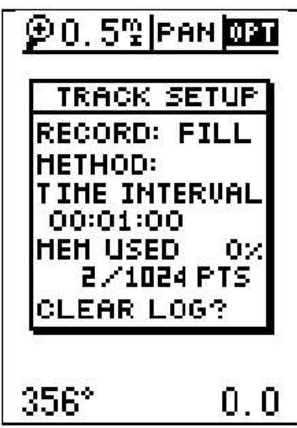

Fig. 3- Telas do GPS navegador. Em a) mostra o erro estimado de posição (EPE), neste caso 15 metros; em b) mostra as opções para a gravação automática de pontos (Tracking).

Na opção automática da Figura 3b, o tempo de permanência no ponto amostral de 30 minutos, por exemplo, gerará 30 pontos (Trackpoints), os quais podem ser associados ao ponto marcado manualmente (Waypoint). Esta opção de "tracking" gera um arquivo de pontos que somente pode ser revisado após este ser descarregado no PC (Personal Computer) através de um programa apropriado o visto em Ferreira (2003).

Os testes estatísticos utilizados foram o teste de normalidade dos dados, média e desvio padrão da distribuição dos dados (Box et al., 1978). A análise dos resultados foi realizada por simples comparação dos dados amostrados com os dados mensurados pelo IBGE para os pontos da Rede Fundamental do IBGE.

\section{Resultados}

Em primeiro lugar demonstrou-se a normalidade dos dados, portanto, os dados podem ser tratados estatísticamente através dos parâmetros da distribuiçaõ normalo, como a média e o desvio padrão. Como trata-se de uma medida invariável (Ponto do IBGE), a dispersão dos valores das indicações é atribuída aos efeitos dos erros aleatórios do sistema de medição. A distribuição dos valores das indicações obtidas, mostrada na Figura 4, agrupa-se em torno do valor central médio e tem uma forma que se assemelha a uma distribuição normal.

Na Figura 4 apresenta-se o histograma de freqüência das leituras automáticas do GPS, superposta a curva normal dos parâmetros. Observou-se uma baixa dispersão relativa ao tamanho do pixel TM, quando observada a média da distribuição. Este procedimento 
estatístico elimina o azar de localizar o ponto com uma medição excepcionalmente errada, o que permite ter uma relativa certeza da posição do pixel amostrado.
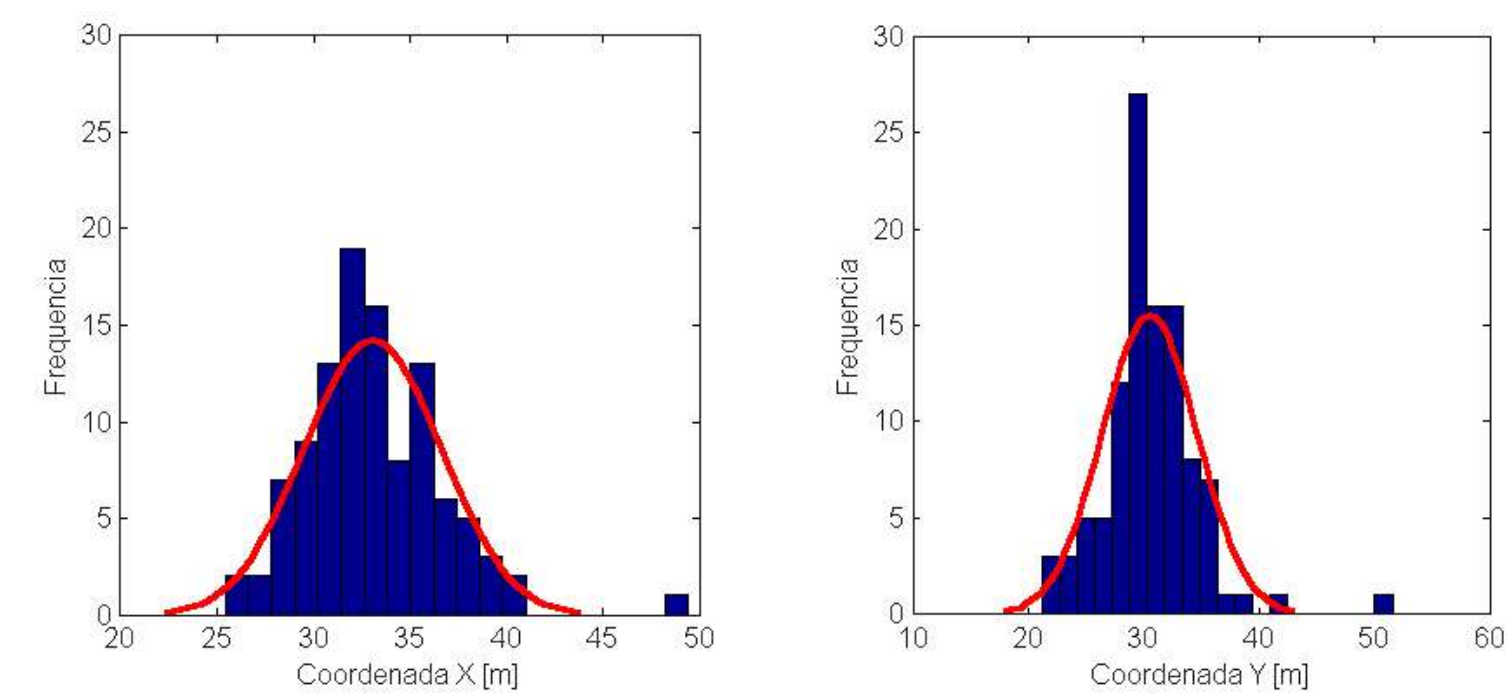

Fig. 4 - Observação gráfica de normalidade dos dados, mostra o ajuste à curva do sino da distribuição normal.

As coordenadas da Figura 4 foram referidas a um ponto imaginário a 40 metros do ponto da amostragem com objetivo de simplificar os dados apresentados nos testes estatísticos. Nas Figura 5 e 6, mostram-se os resultados dos testes de normalidade (normplot de Matlab Statistic Toolbox), onde observam-se um bom ajuste das distribuições com as normais. 


\section{GEOAMBIENTE ON-LINE \\ REVISTA ELETRÔNICA DO CURSO DE GEOGRAFIA DO CAMPUS AVANÇADO DE JATAÍ-GO Http://www.jatai.ufg.br/geo/geoambiente.htm
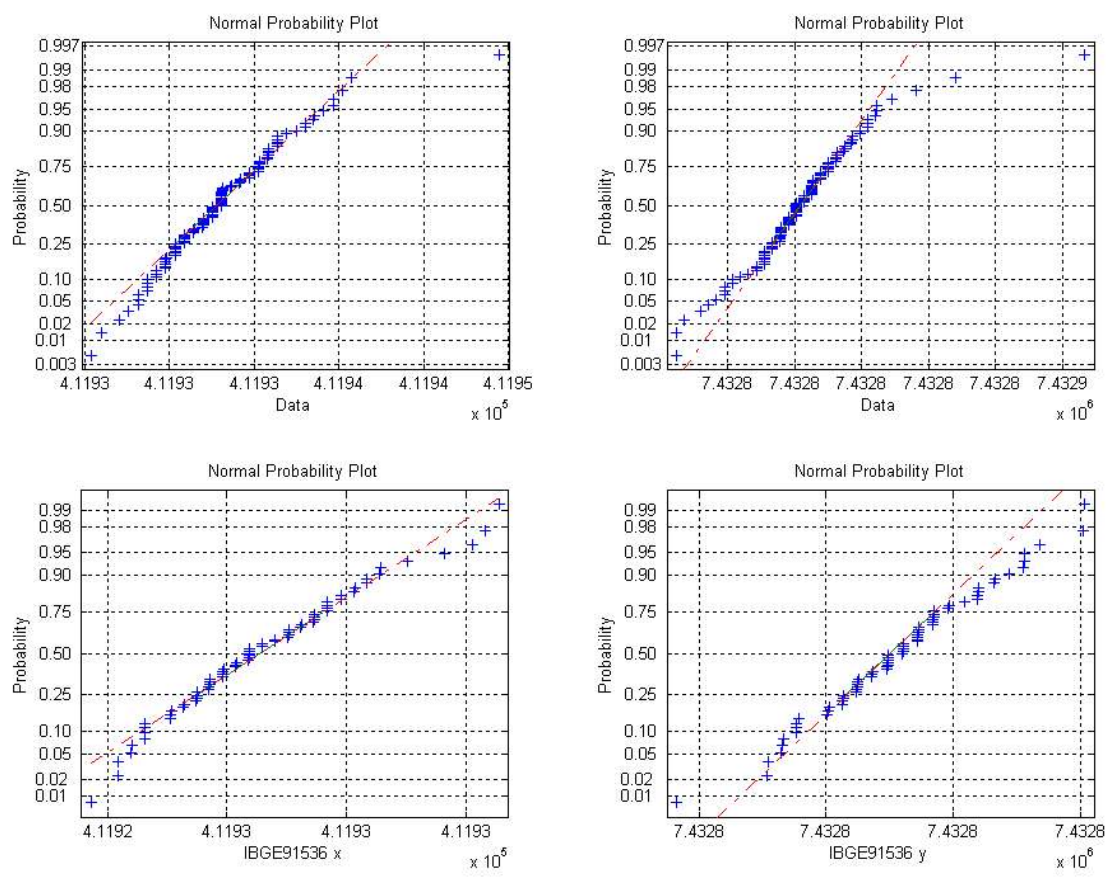

Fig.5 - Teste de normalidade das leituras do GPS navegador no ponto IBGE 91536
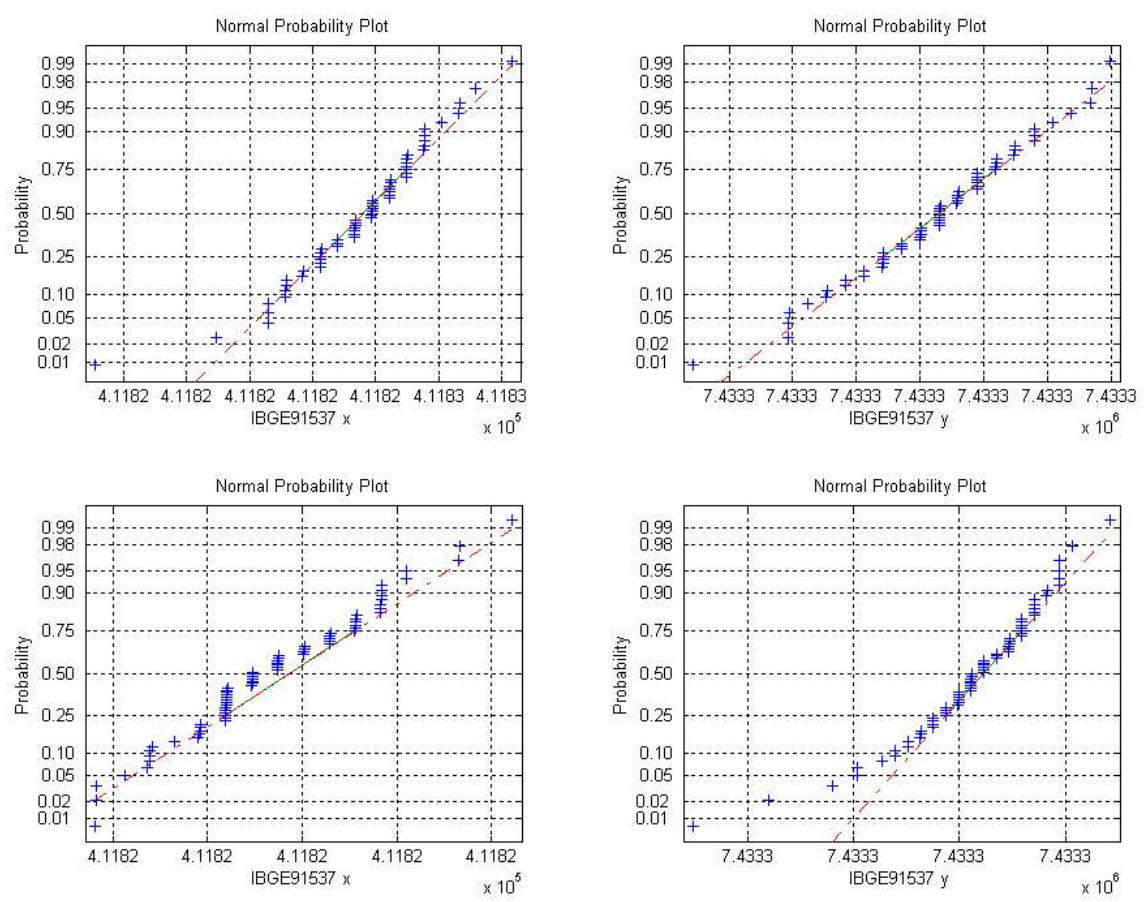
Fig. 6 - Teste de normalidade das leituras do GPS navegador no ponto 91537.

Nas Figuras 6 e 7, observam-se que as distribuições dos pontos são normais embora nos extremos existam pontos muito fora da distribuição, produzidos durante uma deriva anormal das leituras do GPS. A dispersão dos dados após 30 minutos se estabiliza e a média com o tempo vai ficando uma posição a $3 \mathrm{~m}$ em $\mathrm{X}$, e a $6 \mathrm{~m}$ em $\mathrm{Y}$ do valor medido pelo IBGE. Embora os valores medidos oscilem, a média é estável e precisa, permitindo o trabalho cômodo com pixel TM de 30 x 30 metros, quando se necessita localizar o pixel amostrado em aplicações críticas como o treinamento da classificação digital de imagens.

Nas Tabelas 1 e 2 observam-se os valores numéricos das coordenada geográficas UTM WGS84. A média das medições, o desvio padrão $(\sigma)$ e a diferença entre as coordenadas precisas medida pelo IBGE e as médias para X e Y, determinadas estatísticamente com o GPS navegador $(\Delta)$. 
TABELA 1 - PONTO IBGE 91536

\begin{tabular}{cccccccc}
\hline & Medição IBGE & \multicolumn{3}{c}{$1^{\text {a } \text { medição }}$} & \multicolumn{3}{c}{$2^{\text {a medição }}$} \\
& {$[ \pm 1 \mathrm{~mm}]$} & \multicolumn{2}{c}{67 minutos } & \multicolumn{3}{c}{106 minutos } \\
\hline & Coordenada & Coordenada & $\sigma$ & $\Delta$ & Coordenada & $\sigma$ & $\Delta$ \\
& {$[\mathrm{m}]$} & {$[\mathrm{m}]$} & {$[\mathrm{m}]$} & {$[\mathrm{m}]$} & {$[\mathrm{m}]$} & {$[\mathrm{m}]$} & {$[\mathrm{m}]$} \\
$\mathrm{X}[\mathrm{m}]$ & 411929.199 & 411926.474 & 3.843 & 2.725 & 411933.065 & 3.554 & 3.865 \\
$\mathrm{Y}[\mathrm{m}]$ & 7432838.667 & 7432832.836 & 3.124 & 5.831 & 7432830.521 & 4.129 & 8.146 \\
\hline
\end{tabular}

TABELA 2 - PONTO IBGE 91537

\begin{tabular}{cccccccc}
\hline & Medição IBGE & \multicolumn{3}{c}{$1^{\text {a }}$ medição } & \multicolumn{3}{c}{$2^{\text {a medição }}$} \\
& {$[ \pm 1 \mathrm{~mm}]$} & \multicolumn{2}{c}{58 minutos } & \multicolumn{3}{c}{70 minutos } \\
\hline & Coordenada & Coordenada & $\sigma$ & $\Delta$ & Coordenada & $\sigma$ & $\Delta$ \\
& {$[\mathrm{m}]$} & {$[\mathrm{m}]$} & {$[\mathrm{m}]$} & {$[\mathrm{m}]$} & {$[\mathrm{m}]$} & {$[\mathrm{m}]$} & {$[\mathrm{m}]$} \\
$\mathrm{X}[\mathrm{m}]$ & 411820.815 & 411823.538 & 2.149 & 2.724 & 411819.386 & 1.916 & 1.429 \\
$\mathrm{Y}[\mathrm{m}]$ & 7433289.129 & 7433282.553 & 2.615 & 6.576 & 7433285.627 & 3.252 & 3.501 \\
\hline
\end{tabular}

A seguir se apresenta a evolução no tempo da média no caso da coleta de 106 amostras sobre o ponto IBGE 91536. Pode-se observar que após 30 minutos de coleta de dados ocorre uma estabilização a uma distância de 4 metros em X e de 8 metros em Y (Figura 7). Esta diferença indica o limite na acurácea que pode ser obtida com a média, Gurgel (2003, com. pers). 
a

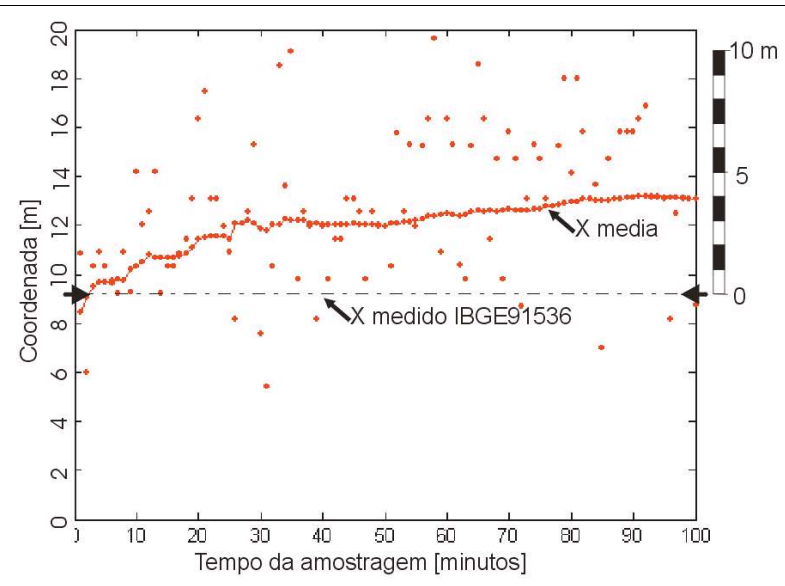

$\mathrm{b}$

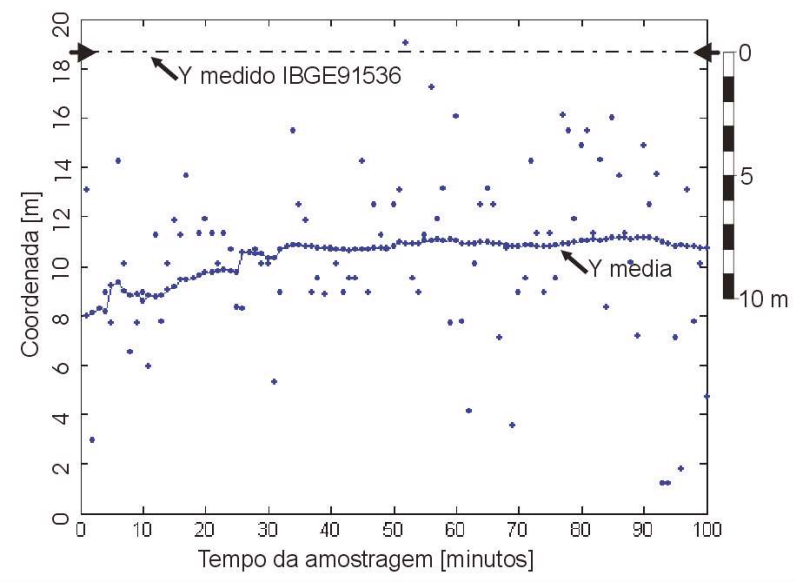

Fig. 7 - Evolução da media das coordenada ao longo do tempo de coleta.

A média se estabiliza aproximadamente após 30 minutos. $\mathrm{O}$ importante é a estabilidade alcançada pela média, a que brinda confiabilidade ao posicionamento do ponto. O tempo maior de coleta de pontos não melhora a precisão após 40 minutos, como pode-se observar através da média nas Figuras 7, tambem observado através do desvio padrão $(\sigma)$ na Figura 8 . 


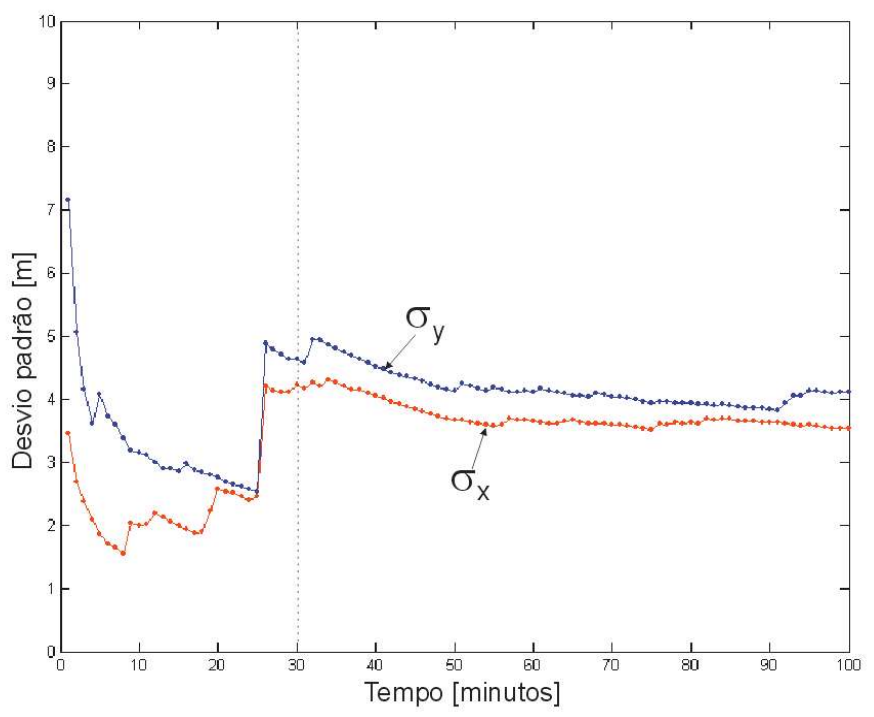

Fig. 8 - O desvio padrão se estabiliza após 30 minutos de coleta, com dispersão de $4 \mathrm{~m}$ dos dados normais.

Após 20 minutos da coleta, verifica-se uma dispersão consistente e aceitável, da ordem de 3 metros, o que permite posicionar o ponto com muita confiança dentro de um pixel com resolução espacial de 30m, como os das imagens TM. Entretanto, observa-se uma mudança brusca na disperção dos dados aos 30 minutos da coleta, em função da mudança na constelação dos satélites. Por isso, não compensa extender muito o tempo de coleta.

\section{Conclusões e Recomendações}

Em um levantamento de campo, o tempo de permanência em cada ponto, em levantamento de solos ou vegetação, geralmente esta na ordem de meia hora, o que permitiria a tomada automática de 20 pontos do GPS, os que seriam recomendados para ser realizada a média estatística e obter a localização do pixel adequada para as técnicas de sensoriamento remoto, pois aos 20 minutos ocorre a estabilização dos valores dos pontos com baixa dispersão.

Portanto, pode ser obtida uma boa precisão de localização, embora o receptor de GPS seja um navegador de baixo custo. O principal aporte desta técnica é aumentar a 


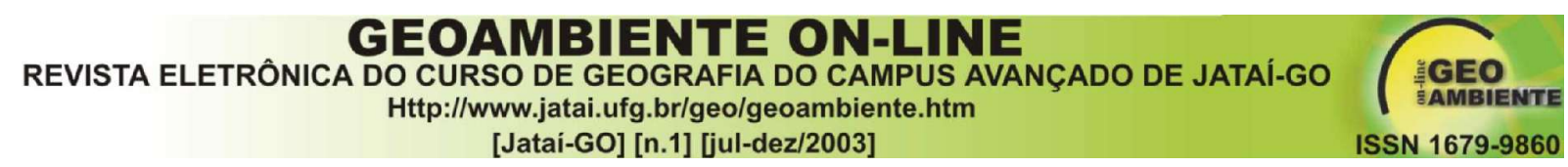

confiabilidade da posição dos pontos amostrais, e secundariamente o aumento da precisão de posição, assim o número de pontos está relacionado com o aumento da confiablidade frente à deriva do GPS.

$\mathrm{Na}$ Figura 9 apresenta-se um fluxograma da metodologia recomendada para uma campanha de levantamento, na qual as medias de cada pontos são rotulados automaticamente com o número do ponto marcado manualmente (waypoint) no receptor GPS.

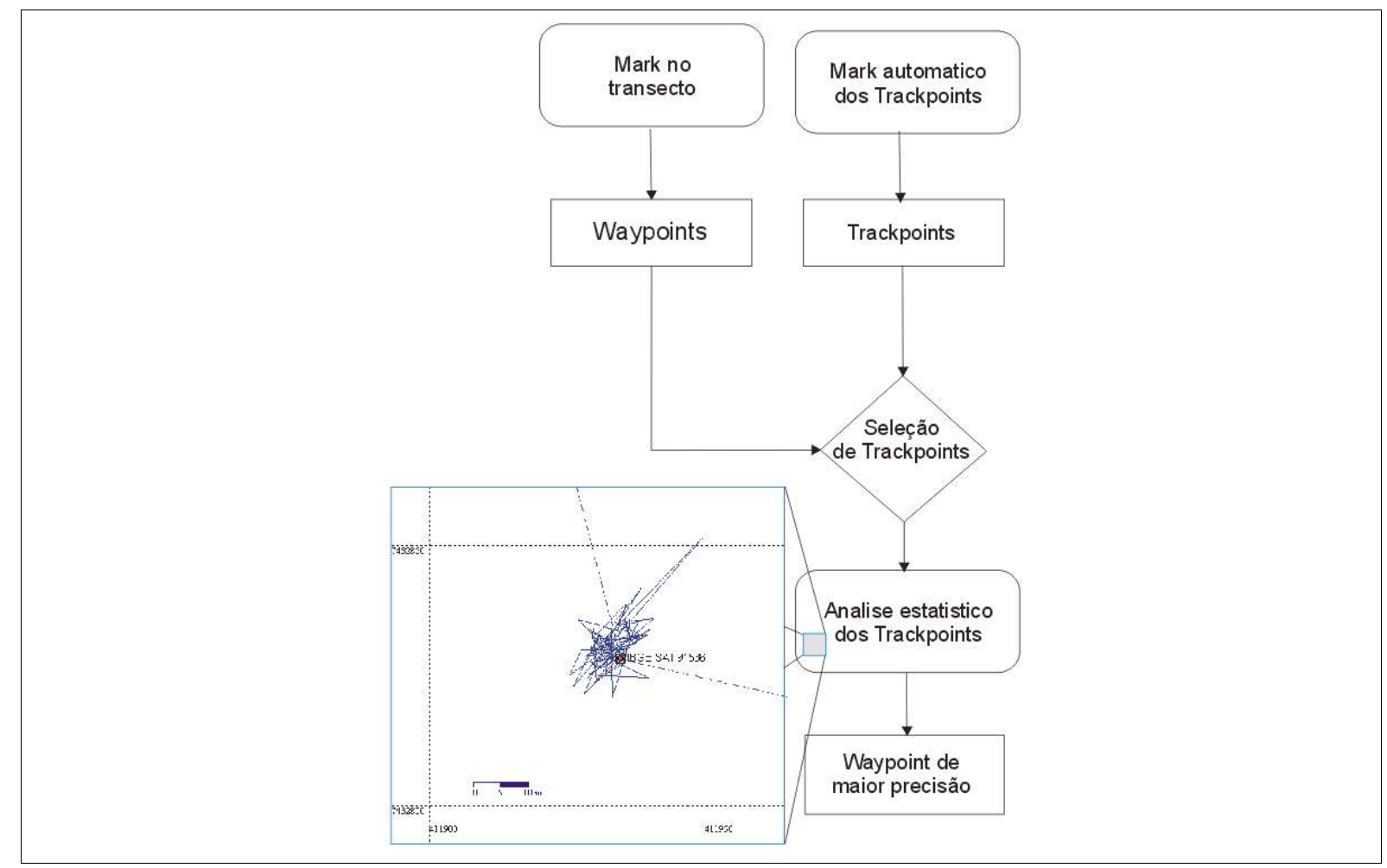

Fig. 9 - Fluxograma da Técnica proposta para o aumento da precisão.

Desta forma, a técnica de posicionamento está formada pelo tratamento estatístico dos pontos obtidos automaticamente pelo receptor (Trackpoint) e do ponto marcado que identifica o local amostral (Waypoint). Este ponto associado à amostra é transformado num ponto mais acurado pelo tratamento estatístico dos pontos vizinhos (Trackpoints).

O tempo do levantamento botânico, como o exemplificado neste trabalho, é suficiente para obter adequada precisão de localização para determinar qual foi o pixel amostrado na imagem. A georreferenciação das imagens utilizando GPS também pode ser beneficiada 


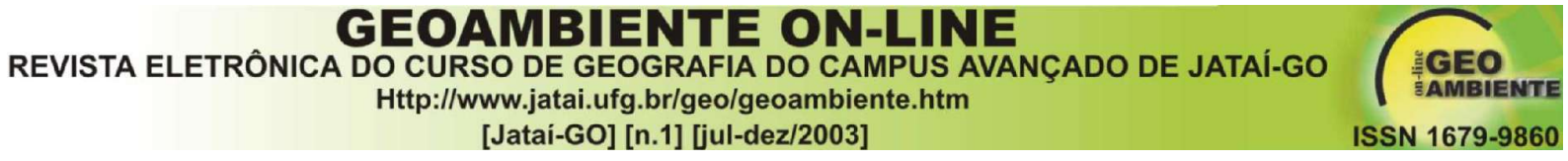

utilizando esta técnica. Embora a utilização desta técnica seja de baixo custo, para campanhas longas se torna imprescindível à utilização periódica de um computador para descarregar os dados da amostragem automática do GPS.

\section{Bibliografia}

Airleve. Simplesmente GPS. 2003. [online]. <http://www.abordo.com.br/ lincoln/gps.htm> Agosto 2003.

Box, G. E.; Hunter, W.G.; Hunter, J.S. Statistic for experimenters. Na Introduction to Design, Data Analysis, and Model Building. New York: John Wiley \& Son, 1978.

IBGE. Pontos da Rede Fundamental. Campanha CTA/IAE-INPE-CTA/ITA. 2003.

Ferreira, O. Trackmaker. Communication Program for GPS and Data Treatment. 2003. [online]. <http://www.gpstm.com/>. Agosto 2003.

Gurgel, P. 2003. Divisão de Sensoriamento Remoto. Instituto Nacional de Pesquisas Espaciais- MCT/INPE. Brasil. Comunicação pessoal. 2003.

Mehaffrey, J.; Yaezel, J. GPS Receiver Information. 2003. [online]. $<$ http://gpsinformation.net/> . Agosto 2003.

Wilson, D. L. Wilson's GPS Accuracy Web Page. 2003. [online]. $<$ http://users.erols.com/dlwilson/gps.htm> Agosto 2003. 